\title{
Physico-chemical evaluation of Gastroretentive Ranitidine Hydrochloride: An Anti-Ulcer Drug
}

\author{
Yadav RK ${ }^{1}$, Prakash $S^{* 2}$, Yadav K ${ }^{3}$, Yadav NK $^{4}$, Mostafa $M^{5}$
}

\author{
Department of Pharmacology, Bangladesh Agricultural University
}

Mymensingh, Bangladesh

\begin{abstract}
${ }^{1}$ Assistant Professor, Department of Pharmacology, Janaki Medical College, Janakpur, Nepal
${ }^{2}$ Assistant Professor, Department of Biochemistry, Janaki Medical College, Janakpur, Nepal

${ }^{3}$ Medical Microbiologist \& Lecturer, Krishna Medical Technical Research Center, Janakpur, Nepal

${ }^{4}$ Associate Professor, Department of Pharmacology, Janaki Medical College, Janakpur, Nepal

${ }^{5}$ Professor, Department of Pharmacology, Bangladesh Agricultural University, Mymensingh, Bangladesh.
\end{abstract}

ABSTRACT

Background and Objectives: The prevention and treatment of peptic ulcers has become an important challenge in the current medicine world. Modern progress in novel drug delivery system aims to improve the efficacy of the drug molecule by formulating a dosage form of RHCL. One of the most feasible approaches for achieving a prolonged and predictable drug delivery profile in GI tract is to control the gastric residence time. Therefore, a multi-unit gastro retentive dosage form of RHCL capable of floating on simulated gastric fluid for more than 12 hours was formulated and evaluated.

Materials and Methods: Nine batches of the light liquid paraffin entrapped emulsion gel beads were prepared by a new emulsion gelation technique using sodium alginate and xanthan gum as polymers. The polymeric solution was extruded into Calcium chloride solution by the use of $21 \mathrm{G}$ needles. Morphology of beads, drug content, drug entrapment efficiency, floating lag time and buoyancy were studied. Compatibility study of Ranitidine $\mathrm{HCl}$ with polymers used in the formulation was performed using DSC and FT-IR.

Results: Mean surface diameter were between $1.220 \pm 2.259 \%$ (F1) to $1.230 \pm 2.316 \%$ (F9) and floating lag time were between 6 minute (F9) to 11 minute (F1). All formulations were buoyant for more than 12 hours in simulated gastric fluid at $37^{\circ} \mathrm{C}$. The drug content and drug entrapment efficiency among the formulations were between $17.48 \% \sim 19.68 \%$ and $71.06 \% \sim 84.32 \%$ respectively. Formulation F1 showed lowest drug content and drug entrapment efficiency while F9 showed highest drug content and drug entrapment efficiency. F4 showed most acceptable sustained drug release profile.

Conclusion: The gastro retentive drug delivery system designed as floating beads was found to be satisfactory drug delivery system for Ranitidine $\mathrm{HCl}$ to improve the bioavailability of the drug.

Key words: Ranitidine, Peptic Ulcer, Drug development

\section{INTRODUCTION}

The design of effective and safe new drug delivery systems has become an integral part for the development and formulating new medicines. Recent scientific and patent literature in academic, industrial, pharmaceutical and medical research has an 
increased interest in novel dosage forms that are retained in the stomach for a prolonged and predictable period of time in gastrointestinal tract [1].

Peptic ulcers have become one of the major human illness affecting nearly $8-10 \%$ of the global population [2], and of these number, $5 \%$ suffer from gastric ulcers [3]. Ranitidine hydrochloride (RHCL) is an anti-ulcer drug that has been extensively used as model drug in prophylaxis and treatment of gastric ulcer, duodenal ulceration, stomach ulcer, gastritis, gastroesophageal reflux, Zollinger-Ellison syndrome and elevated stomach hypersecretion in endocrine multiple adenoma [4-8]. It is a $\mathrm{H}_{2}$ receptor antagonist which competitively inhibits gastric acid secretion with interaction of histamine with its receptors. In addition, it also inhibits acid secretion elicited by gastrin, muscarine, agonists and food etc. [9]. The short biological half-life of the drug is approximately 2.5-3 hours which also favors development of a sustained release formulation. The recommended adult oral dosage of ranitidine is $150 \mathrm{mg}$ twice daily or $300 \mathrm{mg}$ once daily. The effective treatment of erosive esophagitis requires administration of $150 \mathrm{mg}$ of ranitidine 4 times a day. [10,11]. A conventional dose of $150 \mathrm{mg}$ can inhibit gastric acid secretion up to 5 hours but not up to 10 hours. An alternative dose of $300 \mathrm{mg}$ leads to plasma fluctuations, consequently a sustained-release dosage form of $\mathrm{RHCl}$ is desirable [12].

Preparation of floating alginate beads is more appropriate and is a multiparticulate system which utilizes cheap and nontoxic polymers with no use of any organic solvent [13-16]. Sodium alginate is a natural polysaccharide and a linear co-polymer composed of two monomeric units as D-mannuronic acid and
L-guluronic acid obtained from brown algae which shows gelling properties in the presence of divalent cations such as $\mathrm{Ca}^{2+}, \mathrm{Sr}^{2+}$ or $\mathrm{Zn}^{2+}$ [17]. It is widely used in various controlled release dosage form due to its natural, biodegradable or mechanical and hydro-gel forming properties, which also reduces interfacial tension between an oil and water phase and is efficient for preparation of emulsion $[18,19]$.

Formulation of $\mathrm{RHCl}$ as a sustained release dosage form can also minimize the loss of drug in comparison of conventional tablets. Out of the available category of drugs for the treatment of ulcer, $\mathrm{H}_{2}$ antagonists class of drugs like Famotidine, Ranitidine are considered to be the safest drugs available and hence this drug has promising future if controlled release formulations are made [5]. But some literature found on colonic metabolism of Ranitidine $\mathrm{HCI}$ is partly responsible for its poor bioavailability [4, 9]. These properties do not favour a traditional approach to sustained release delivery. Thus a sustained and controlled release dosage form of ranitidine hydrochloride is desirable. Therefore, the present study was focused to design the formulating floating beads of Ranitidine $\mathrm{HCl}$ using combination of polymers sodium alginate and xanthan gum to improve the release profile of the drug and also target it to stomach and upper intestine via gastroretention for its bioavailability and prolonged local action for better patient compliance.

\section{MATERIAL AND METHODS}

\section{Study design}

The experimental research based study was conducted at Department of Pharmacology, Bangladesh Agricultural University, Mymensingh, in 2014 AD. The sample of 
RHCL was obtained from Beacon Pharmaceuticals Limited Kathali, Bhaluka, Mymensingh, Bangladesh. Nine batches of the light liquid paraffin entrapped emulsion gel beads were prepared by a new emulsion gelation technique using sodium alginate and xanthan gum as polymers.

\section{Sample Selection and Processing}

Altogether 10 dried beads were randomly selected from each batch for the present study.

\section{Preparation of RHCl beads}

1. Dispensing: API and all other ingredients were weighed properly.

2. Preparation of polymeric solution: Polymers were dissolved gradually in required amount of distilled water with vigorous stirring.

3. Addition of drug and oil: Ranitidine hydrochloride and Light Liquid Paraffin were added into the polymeric solution.

4. Homogenization of the mixture: The mixture of Drug, Polymers and Oil were homogenized for 15 minutes at $1000 \mathrm{rpm}$.

5. Extrusion: The mixture extruded through $21 \mathrm{G}$ specially modified needles into $5 \% \mathrm{CaCl} 2$ solution from $5 \mathrm{~cm}$ distance at a rate of $2 \mathrm{ml} / \mathrm{min}$.

6. Filtration and separation: The formed beads separated from solution by filtration through mesh100 and washed using distilled water.

7. Drying: Formed beads dried at 40 $45^{\circ} \mathrm{C}$ until constant weight was achieved.

\section{Physico-chemical evaluation of RHCl emulsion gel beads:}

The prepared beads were evaluated for following characteristics i.e.

\section{Size and Morphological study}

Color and shape of dried beads of each batch was observed under trinocular and light microscope. The diameter of beads was determined by using micrometer and calculated.

Buoyancy Study in Vitro: The time between the introduction of the beads into the medium and its buoyancy to the upper one third of the dissolution vessel (floating lag time) and the time for which the formulation constantly floated on the surface of the medium (floating duration) were measured simultaneously.

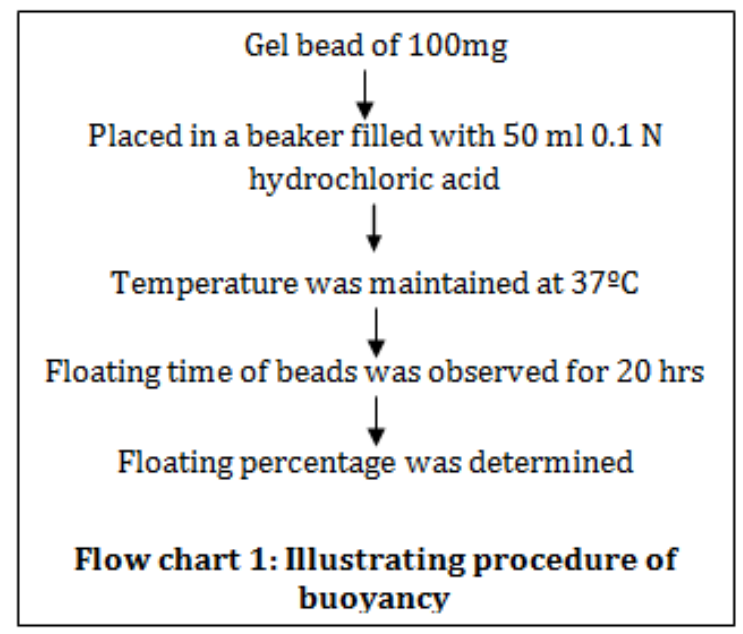

Determination of drug content and entrapment efficiency: The drug content and entrapment efficiency were determined by the following equations:

$\%$ Drug content $=\frac{\text { Weight of drug present in beads (gms) }}{\text { Weight of quantity of beads (gms) }} \times 100$

$\%$ Entrapment efficiency $=\frac{\text { Theoretical drug content }}{\text { Experimental drug content }} \times 100$ 
Determination of Swelling Index: Beads were studied for swelling characteristics. Only those batches were selected which have good drug content and entrapment efficiency more than 50\%. The swelling index was calculated using the following formula:

Swelling index $=\underline{\text { Final wt, of beads }- \text { Initial wt. of beads }} \times 100 \%$ Initial wt. of beads

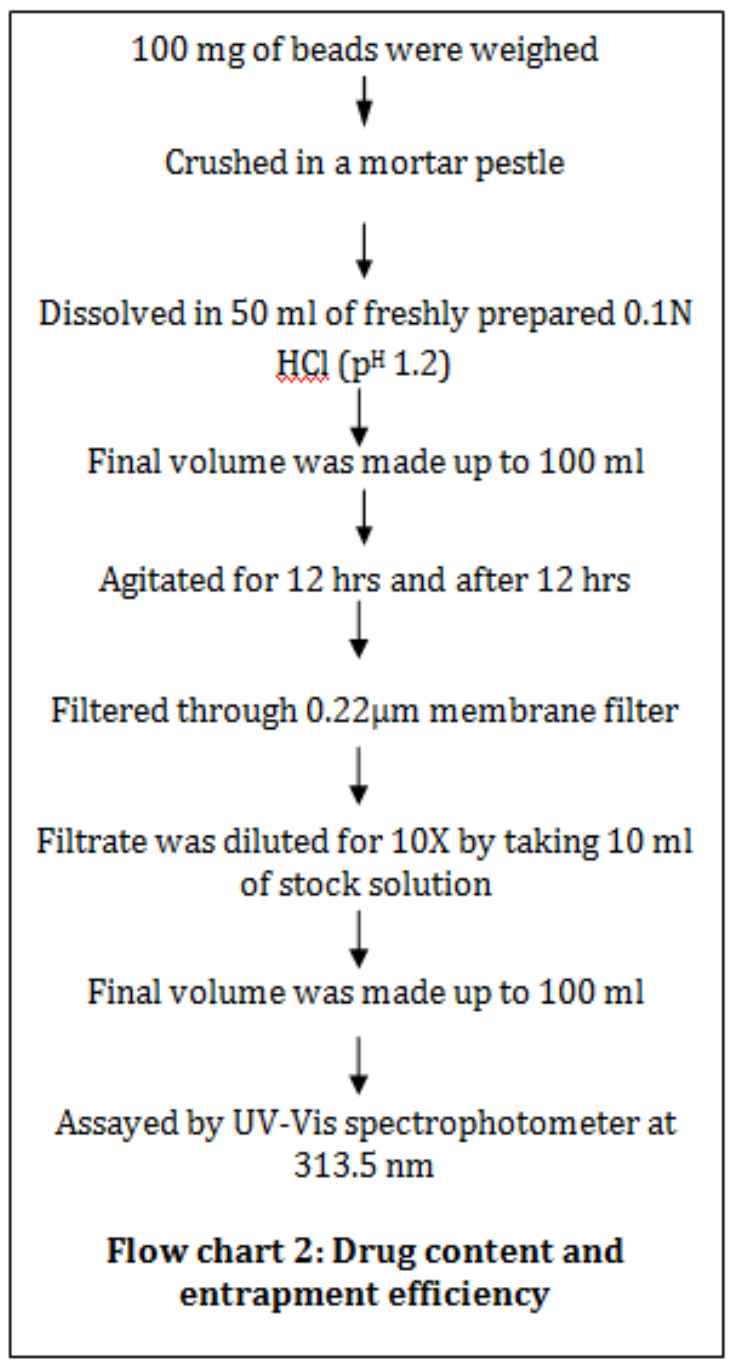

Drug Release Study: Only those batches were selected for the release study, which have good drug content and drug entrapment efficiency more than $50 \%$.

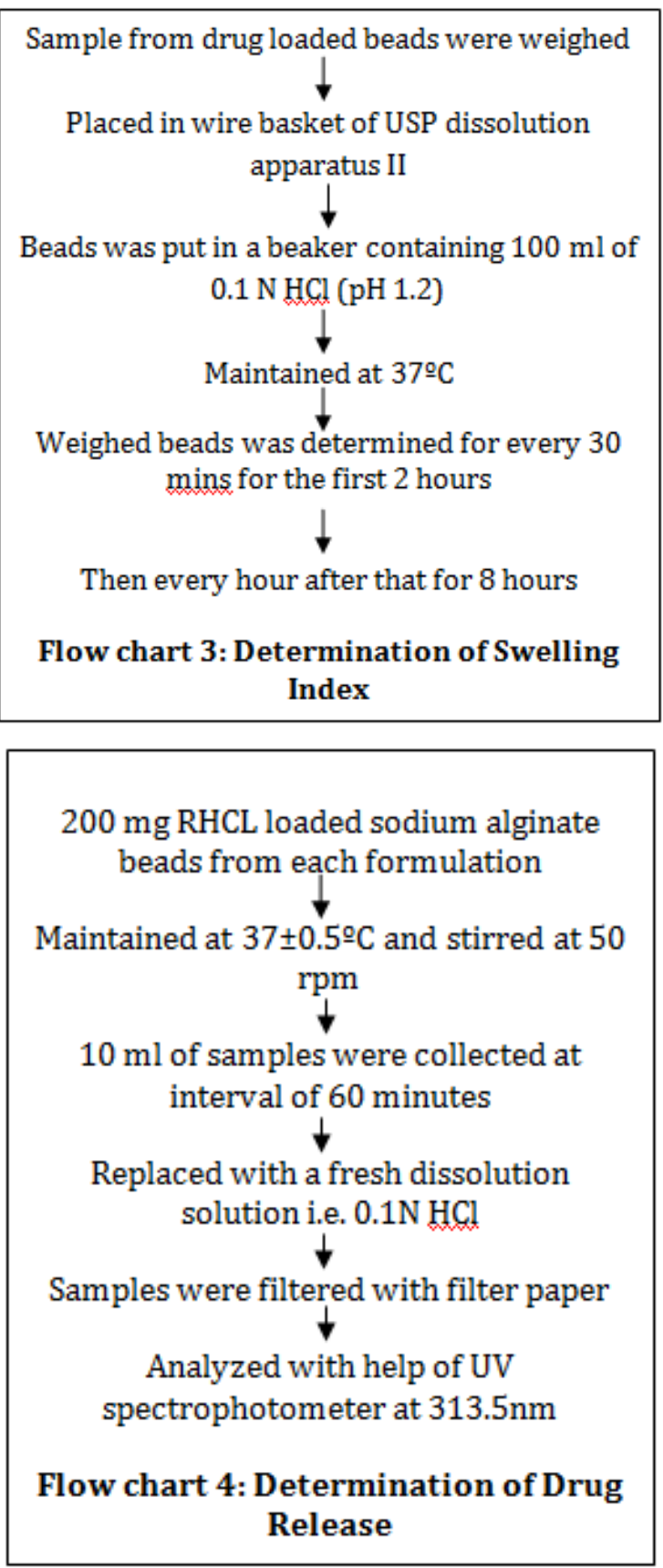

\section{RESULTS}

Physical properties of dried oil entrapped sodium alginate emulsion gel of each beads of RHCl: Transparency of the beads was directly proportional to the amount of xanthan gum and inversely proportional to the amount of sodium alginate. Formulation F3, F6 and F9 are more transparent than 
other where F3 has the highest transparency. The highest yield percentage of oil entrapped sodium alginate emulsion gel beads of $\mathrm{RHCl}$ was found to be $98.43 \%$ in $\mathrm{F} 6$ followed by $\mathrm{F} 1$ with $97.47 \%$. The results are shown in Figure1.

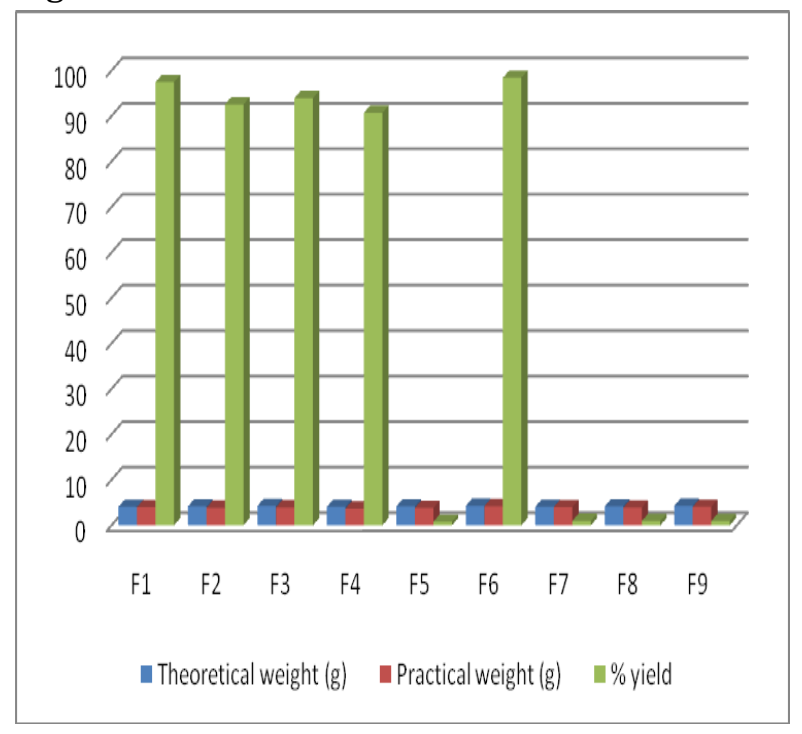

Figure 1: Yield percentage of gel beads of RHCl

The mean surface diameters of all the batches of oil entrapped sodium alginate emulsion gel beads of RHCl were between $1.220 \pm 2.259 \%$ to $1.230 \pm 2.316 \%$. The results are shown in table 1.

Table 1: Morphology and mean surface diameters of all the batches of gel beads

\begin{tabular}{|l|l|l|}
\hline Formulation & $\begin{array}{l}\text { Mean diameter } \pm \\
\text { RSD (\%) }\end{array}$ & $\begin{array}{l}\text { Shape of } \\
\text { beads }\end{array}$ \\
\hline F1 & $1.220 \pm 2.259$ & \multirow{2}{*}{$\begin{array}{c}\text { All batches } \\
\text { of each } \\
\text { beads had } \\
\text { spherical } \\
\text { shape }\end{array}$} \\
\cline { 1 - 2 } F3 & $1.224 \pm 0.631$ & \\
\hline F4 & $1.227 \pm 2.553$ & \\
\hline F6 & $1.222 \pm 2.258$ & \\
\hline F7 & $1.225 \pm 1.214$ & \\
\hline F8 & $1.228 \pm 2.273$ & $1.223 \pm 1.541$ \\
\hline
\end{tabular}

Buoyancy of RHCl emulsion gel beads in 0.1N HCl: For all the batches the floating time was above 12 hours and floating percentage of $\mathrm{RHCl}$ emulsion gel beads was 100\% which showed good floatability but different formulation shows different floating lag time ranges from 6-11 minutes. The results are shown in figure 2.

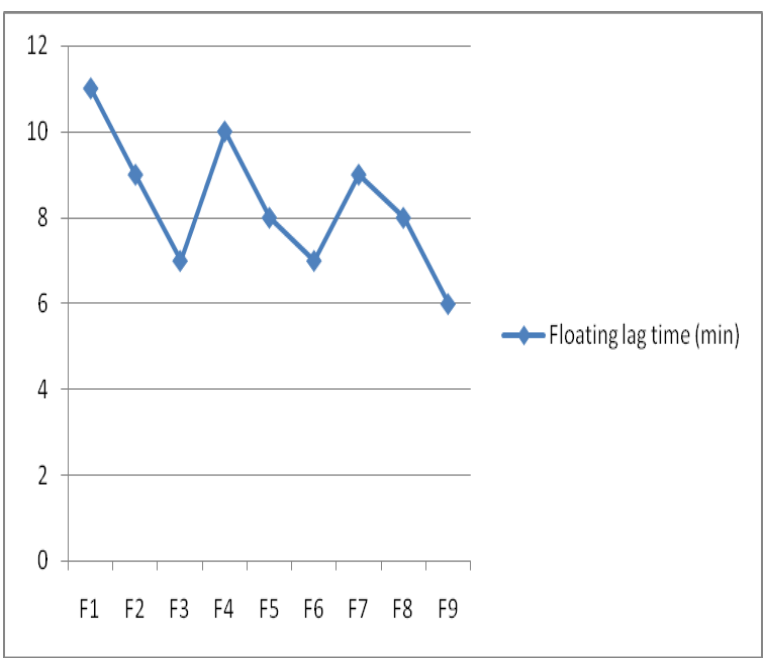

Figure 2: Floating lag time (min) ranges of different formulation

Swelling index of RHCl emulsion gel beads at different time intervals: There was a maximum swelling of beads in F6 in 1hour followed by sudden reduction in weight in third observation. In batch F1, F2 \& F3, batch F4, F5 \& F6, batch F7, F8 \& F9, the increased amount of xanthan gum in each pair of batches revealed a slower swelling of beads. The results are shown in table 2 .

Pattern of Drug content and Entrapment Efficiency (EE) of different formulations of RHCl floating emulsion gel beads: This study showed that the drug entrapment efficiency of the dried beads varied from $17.48 \%$ to $84.32 \%$ and drug content of beads had range from $17.48 \%$ to $19.68 \%$. The highest percentage of entrapment efficiency of beads was observed in F9 (84.32\%) followed by F3 (82.22\%) and in drug content was $19.68 \%$ and $19.28 \%$ respectively. The results are shown in Figure 3. 


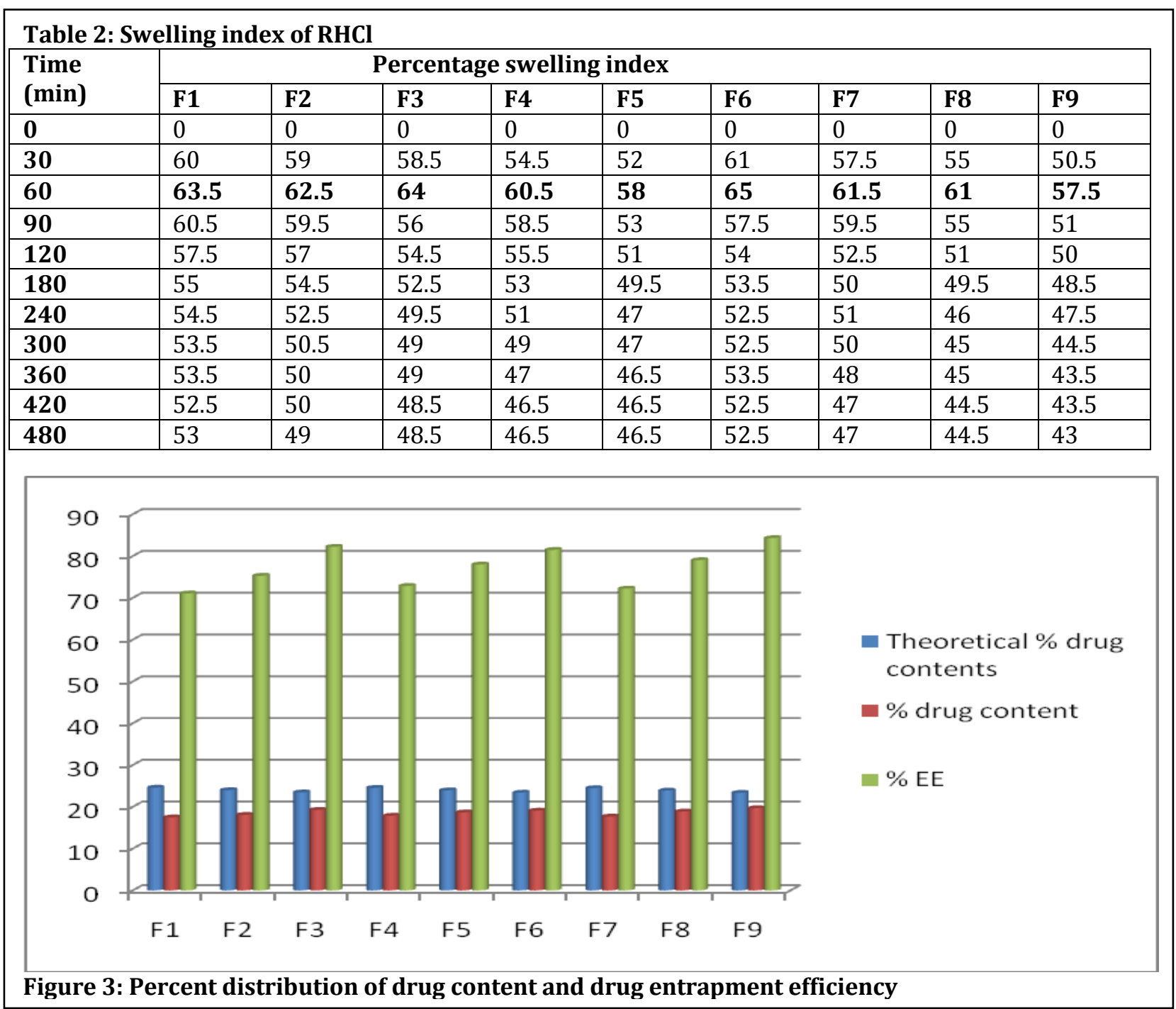

\section{DISCUSSION}

Gastric mucus plays an important role in the gastric ulcer defense mechanism, whereby it forms a continuous mucus gel-like protective barrier coating the entire gastric mucosa that maintains the mucosal surface at a $\mathrm{pH}$ of 6-7 in the acidic environment ( $\mathrm{pH} 1-2$ ). In gastric ulcers, in spite of low acid secretion, weakening of mucosal defenses can also lead to severe injury. The inhibition of gastric acid secretion is a key therapeutic target for the ulcer diseases [20]. A drug that is released from a dosage form in a controlled manner in the stomach will empty together with fluids and will have the whole surface area of the small intestine available for absorption [21]. These considerations have lead to the development of oral controlled gastro retentive dosage forms possessing gastric retention capabilities. Thus, Gastroretentive dosage forms, i.e. those designed to exhibit a prolonged gastric residence time. The alginate molecule occur as regions made up exclusively of one unit or the other referred to $\mathrm{M}$ block or $\mathrm{G}$ block or as a region in which monomer approximates an alternating sequence for GRT. 
This study revealed morphological examination of the surface structure of the dried oil entrapped sodium alginate emulsion gel of each beads of $\mathrm{RHCl}$ were spherical and the surface had rough texture which may be due to entrapment of oil globules. An almost similar finding was also obtained in the study conducted by Jaiswal D et al [9]. The colors of beads were off white but the deepness of the color was directly proportional to the amount of sodium alginate in beads in this study.

Transparency of the beads was directly proportional to the amount of xanthan gum and inversely proportional to the amount of sodium alginate. Formulation F3, F6 and F9 are more transparent than other where F3 has the highest transparency. The highest yield percentage of oil entrapped sodium alginate emulsion gel beads of $\mathrm{RHCl}$ was found to be $98.43 \%$ in F6 followed by F1 with 97.47\% (Figure1). Trinucular microscopic view of $\mathrm{RHCl}$ floating emulsion gel beads showed off white in color with good sphericity and texture which may be due to mineral oil. The mean surface diameters of all the batches of oil entrapped sodium alginate emulsion gel beads of $\mathrm{RHCl}$ were between $1.220 \pm 2.259 \%$ to $1.230 \pm 2.316 \%$ (table 1 ). It suggests that the size of the emulsion gel beads were directly proportional to the amount of the polymer in formulations which may be due to the concentration of polymeric solution.

For all the batches the floating time was above 12 hours and floating percentage of RHCl emulsion gel beads was $100 \%$ which showed good floatability but different formulation shows different floating lag time ranges from 6-11 minutes (figure 2). This reflects floating lag time was directly proportional to the amount of polymers in the beads. The mineral oil reduced the floating lag time and enhanced the floating time as well as floating percentage. Very minor amount of oil leakage was observed in case of $\mathrm{F} 1$ in $0.1 \mathrm{~N} \mathrm{HCl}$. Jaiswal D et al reported that most of the batches had floating time more than $20 \mathrm{hrs}$ but they have different floating lag time which is in accordance with this study [9]. In the study conducted by Tiwari AK et al reported the \% buoyancy was found in range of $67 \%$ to $89 \%$. In formulation $\mathrm{F} 1$ to $\mathrm{F} 3$, as the concentration of polymer increased, \% buoyancy is decreased from $75.39 \%$ to $67.12 \%$ [4]. Same as in formulation F4 to F6, \% buoyancy decreased from $89.39 \%$ to $79.34 \%$ and in formulation F5 to F6, \% buoyancy decreased from $84.33 \%$ to $76.40 \%$ which is differ from this study.

There was a maximum swelling of beads in F6 in 1 hour followed by sudden reduction in weight in third observation in each batch which might be due to acid solubility of drug. The polymer concentration and polymer mixture ratio have significant effect on swelling index of beads. The swelling indexes of beads were inversely proportional to the amount of polymer in formulations which may be due to maximum cross linking of polymers that yielded compact beads. As the proportion of alginate was increased, the swelling ratio decreased which proves alginate makes compact structured beads. In batch F1, F2 \& F3, batch F4, F5 \& F6, batch F7, F8 \& F9, the increased amount of xanthan gum in each pair of batches revealed a slower swelling of beads (table 2). The similar findings were also obtained in the study conducted by Bhimavarapu R et al [22].

This study represented the drug entrapment efficiency of the dried beads was varied from $17.48 \%$ to $84.32 \%$ and drug content of beads had range from $17.48 \%$ to $19.68 \%$. The highest percentage of entrapment efficiency 
of beads was observed in F9 (84.32\%) followed by F3 (82.22\%) and in drug content was $19.68 \%$ and $19.28 \%$ respectively (figure $3)$. The drug entrapment efficiency of the dried beads was varied from 2.11 to $75.18 \%$ and drug content of beads had range from $0.5 \%$ to $26.75 \%$ in the study performed by Jaiswal D et al [9]. The results showed that the drug content and drug entrapment efficiency were directly proportional to the amount of polymers in formulations. As the polymer was cross linked complexly at higher concentration, it can be said that at definite curing time drug diffusion in surrounding aqueous medium were inversely proportional to the concentration of polymer solution. As the amount sodium alginate increased the gelification was rapid thus had greater drug entrapment.

Most of the drug diffused in the surrounding aqueous medium results very low \% drug content and \% entrapment efficiency. Being Ranitidine hydrochloride a freely water soluble drug, to overcome this problem, curing time was optimized at 2 min. Curing time is major factor which governs the percentage of drug content and entrapment efficiency. The \% of drug content and \% of entrapment efficiency was also affected by the ratio of drug and polymer.

\section{CONCLUSION}

The present novel drug floating emulsion gel beads approach for Ranitidine $\mathrm{HCl}$ (prepared with sodium alginate and xanthan gum) enhances GI retention and decreases the frequency of administration. This study concluded that the gastro retentive drug delivery system designed as floating beads was found to be satisfactory drug delivery system for Ranitidine $\mathrm{HCl}$ to improve the bioavailability of the drug.
This gives a signal to extend this approach to similar combinations of drugs used in clinical practice so as to improve bioavailability of poorly absorbed drugs in GI. These beads can entrap even a water soluble drug as Ranitidine hydrochloride in sufficient amount and also can successfully deliver the drug in stomach for a prolong duration of time with the decrease in the concentration of the gas forming agent. Alginate beads loaded with drug are important in the drug delivery by oral route as well as other routes, as sustained and controlled release formulations. As these micro- beads are biocompatible, nontoxic, biodegradable, so they may be better used and i.e. they have paved a better way for controlled/sustained release of drug through the use of natural, biodegradable material. Further study on in vivo release and stability of the beads needs to be performed in clinical studies from stomach ulcers patients.

\section{ACKNOWLEDGEMENT}

Authors acknowledge their deep sense of appreciation to Department of Pharmacology, Bangladesh Agricultural University for providing facilities to carry out this research and are thankful to Beacon Pharmaceuticals Limited, Kathali, Bhaluka, Mymensingh, Bangladesh for providing gift sample of Ranitidine hydrochloride.

\section{REFERENCES}

1. Khan $\mathrm{AD}$ \& Bajpai M. Formulation and Evaluation of Floating beads of Verapamil hydrochloride. Int J Pharm Tech Res 2011; 3(3): 1537-1546.

2. Calam J, Baron HJ Pathophysiology of duodenal and gastric ulcer and gastric cancer. Br Med J 2001; 323: 980-983.

3. Bandyopadhyay D, Biswas KM. Bhattacharyya M, Reiter JR, Banerjee RK. Involvement of reactive oxygen species in gastric ulceration, protection by melatonin. Ind J Exp Biol 2002; 40: 693-705. 
4. Tiwari AK, Patel G, Rabadia N. Formulation And Evaluation Of Floating Microsphere H2 Receptor Blocker Ranitidine HCl By Ionic Gelation Method . Int J Pharma Sci and Res 2012; 3(8): 2801-2808.

5. Goel RK and Shah BS. Elements of Pharmacology. 17th edn. Prakashan publishers; 2008. pp 440-443.

6. Basit A \& Lacey L. Colonic metabolism of ranitidine; implication for its delivery and absorption. Int J Pharm 2001; 227: 157-65

7. Singh BM \& Kim KH, Floating drug delivery system: an approach to oral controlled drug delivery via gastric retention. J Control Rel 2000; 63: 235-239.

8. Mannur VS, Karki SS, Ketan B. Ramani Formulation and Characterization of Ranitidine Hydrochloride Fast Disintegrating Tablets. Int J Chem Tech Res 2010; 2(2): 1163-1169.

9. Jaiswal D, Bhattacharya A, Yadav KI, Singh PH. Formulation and Evaluation of Oil Entrapped Floating Alginate Beads of Ranitidine Hydrochloride. Int J of Pharm and Pharmaceu Sci 2009; 1(1): 129-140.

10. Flynn M, Hagemann RC, Threlkeld DS. Histamine H2 antagonists. In: Drug Facts and Comparisons. 50th ed. St Louis, MO: Wolters Kluwer Co; 1996. pp 1862-1876.

11. Patel MD, Patel MN, Patel FV, Bhatt AD. Floating Granules of Ranitidine Hydrochloride Gelucire 43/01: Formulation Optimization Using Factorial Design. AAPS Pharm Sci Tech 2007; 8 (2): E1-E7.

12. Somade S, Singh K. Comparative evaluation of wet granulation and direct compression methods for preparation of controlled release ranitidine HCL tablets. Ind J Pharm Sci 2002; 64:285.

13. Malviya S, Singh S, Pandey J, Kumar A. Kondalkar, Tagde P. Formulation and evaluation of floating microbeads of ciprofloxacin $\mathrm{HCl}$ by emulsion gelation method. Der Pharmacia Lettre 2013; 5 (2): 63-68 Available online at www.scholarsresearchlibrary.com

14. Rowe RC, Sheskey PJ, Weller PJ, Handbook of Pharmaceutical Excipients. 4th ed. Pharmaceutical press; 1996.

15. Sharma H, Pradhan S, Sarangi. Preparation and in Vitro Evaluation of Enteric Controlled Release Pantoprazole Loaded Microbeads Using Natural Mucoadhesive Substance from Dillenia Indica L. Int J of Pharm Tech Res 2010; 2 (1): 542-551.

16. Singh Y, Tanwar SY, Naruka SP, Garima Rani Ojha RG. Development and evaluation of floating microspheres ofverapamil hydrochloride Revista Brasileira de Ciências Farmacêuticas. Brazilian J Pharmaceu Sci 2007; 43 (4): 24-33.
17. Suksamran T, Opanasopit P, Rojanarata T, Ngawhirunpat T, Ruktanonchai U, Supaphol U. Biodegradable Alginate Microparticles Developed by Electrohydrodynamic Spraying Techniques for Oral Delivery of Protein. J of Microencapsul 2009; 26(7): 563-570.

18. Wise DL. Handbook of Pharmaceutical Controlled release Technology. 2nd ed. Marcel Dekker, Inc. New York; 1996.

19. Bhardwaj TR, Kanwar M, Lal R, Natural gums and modified natural gums as sustained release carriers. Drug Dev Ind Pharm 2000; 26(10): 10251038.

20. Jain KS, Shah AK, Bariwal J, Shelke SM, Kale AP, Jagtap JR, Bhosale A. Recent advances in proton pump inhibitors and management of acid- peptic disorders. Bioorg Med Chem 2007; 15: 1181-1205.

21. Chueh HR, Zia H. Rhodes CT: Optimization of sotalol floating and bioadhessive extended release tablet formulations. Drug Dev and Industr Pharm 1995; 21: 1725-1747.

22. Bhimavarapu R, Nissankararao S, Nagavani $S$, Durga LP. Design, development and in vitro evaluation of gastro retentive alginate floating beads for ranitidine hydrochloride. J Chem and Pharma Res 2013; 5(4): 377-381.

\section{Correspondence to: Satyam Prakash} Assistant Professor, Dept. of Biochemistry Janaki Medical College Teaching Hospital Tribhuvan University, Janakpur- 45600 Email: sprakashy2424@gmail.com 